OPEN ACCESS

Edited by

Jennifer $Y u$,

Western Reserve University,

United States

Reviewed by:

Timothy F. Burns,

University of Pittsburgh, United States

Alessia Pellerino,

University Hospital of the City of Health

and Science of Turin, Italy

${ }^{*}$ Correspondence

Kyle M. Walsh

kyle.walsh@duke.edu

${ }^{\dagger}$ These authors have contributed equally to this work and share

senior authorship

Specialty section: This article was submitted to

Neuro-Oncology and

Neurosurgical Oncology,

a section of the journal

Frontiers in Oncology

Received: 28 September 2021

Accepted: 22 December 2021

Published: 25 January 2022

Citation:

Shen E, Van Swearingen AED,

Price MJ, Bulsara K, Verhaak RGW,

Baëta C, Painter BD, Reitman ZJ, Salama AKS, Clarke JM, Anders CK,

Fecci PE, Goodwin CR and Walsh KM

(2022) A Need for More Molecular

Profiling in Brain Metastases.

Front. Oncol. 11:785064

doi: $10.3389 /$ fonc. 2021.785064

\section{A Need for More Molecular Profiling in Brain Metastases}

\author{
Erica Shen ${ }^{1,2}$, Amanda E. D. Van Swearingen ${ }^{3,4}$, Meghan J. Price ${ }^{5}$, Ketan Bulsara ${ }^{1}$, \\ Roeland G. W. Verhaak ${ }^{1,2,6}$, César Baëta ${ }^{4,5}$, Brice D. Painter ${ }^{4,5}$, Zachary J. Reitman ${ }^{5,7}$, \\ April K. S. Salama ${ }^{3,4}$, Jeffrey M. Clarke ${ }^{3,4}$, Carey K. Anders ${ }^{3,4}$, Peter E. Fecci ${ }^{4,5}$, \\ C. Rory Goodwin ${ }^{4,5 t}$ and Kyle M. Walsh ${ }^{4,5 * t}$
}

\begin{abstract}
${ }^{1}$ Division of Neurosurgery, Department of Surgery, University of Connecticut, Farmington, CT, United States, ${ }^{2}$ The Jackson Laboratory for Genomic Medicine, Farmington, CT, United States, ${ }^{3}$ Division of Medical Oncology, Department of Medicine, Duke University Medical Center, Durham, NC, United States, ${ }^{4}$ Duke Center for Brain and Spine Metastasis, Duke Cancer Institute, Duke University Medical Center, Durham, NC, United States, ${ }^{5}$ Department of Neurosurgery, Duke University Medical Center, Durham, NC, United States, ${ }^{6}$ Department of Neurosurgery, Cancer Center Amsterdam, Amsterdam Universitair Medische Centra (UMC), Vrije Universiteit Amsterdam (VU) University Medical Center (VUmc), Amsterdam, Netherlands, ${ }^{7}$ Department of Radiation Oncology, Duke University Medical Center, Durham, NC, United States
\end{abstract}

As local disease control improves, the public health impact of brain metastases (BrM) continues to grow. Molecular features are frequently different between primary and metastatic tumors as a result of clonal evolution during neoplasm migration, selective pressures imposed by systemic treatments, and differences in the local microenvironment. However, biomarker information in BrM is not routinely obtained despite emerging evidence of its clinical value. We review evidence of discordance in clinically actionable biomarkers between primary tumors, extracranial metastases, and BrM. Although BrM biopsy/resection imposes clinical risks, these risks must be weighed against the potential benefits of assessing biomarkers in BrM. First, new treatment targets unique to a patient's BrM may be identified. Second, as BrM may occur late in a patient's disease course, resistance to initial targeted therapies and/or loss of previously identified biomarkers can occur by the time of occult BrM, rendering initial and other targeted therapies ineffective. Thus, current biomarker data can inform real-time treatment options. Third, biomarker information in BrM may provide useful prognostic information for patients. Appreciating the importance of biomarker analyses in BrM tissue, including how it may identify specific drivers of BrM, is critical for the development of more effective treatment strategies to improve outcomes for this growing patient population.

Keywords: brain metastases, sequencing, biomarkers, neurosurgery, discordance

\section{HIGHLIGHTS}

- The genomic status of BrM can alter treatment plans for patients by providing new targetable options.

- Molecular profiling of BrM can indicate that a therapy is no longer effective for a patient.

- Biomarker information in BrM may provide useful prognostic information for patients. 


\section{INTRODUCTION}

Far exceeding primary central nervous system (CNS) neoplasms in number, metastases to the brain pose a significant societal burden. Of an estimated 1.7 million new cancer diagnoses per year in the United States, approximately $6 \%-14 \%$ of these patients are expected to ultimately develop a metastasis to the brain (1-3). Brain metastases (BrM) most commonly arise in patients with primary lung, breast, and melanoma neoplasms but are also observed in patients with renal cell carcinoma, prostate cancer, colorectal cancer, and many other primary cancer histologies (4).

Patients with BrM face a dismal prognosis, with a median overall survival of $<6$ months regardless of primary cancer type based on historical data $(5,6)$. Clinically actionable molecular biomarkers, such as genetic alterations and aberrant gene expression, have been increasingly identified and translated into treatment options for cancer patients, with more specific emphasis placed on patients with BrM in recent years (7). Identifying accurate molecular biomarkers for BrM is crucial to developing more effective therapies and advancing personalized oncology care.

Modern management of BrM involves multidisciplinary consideration of surgery, radiation therapy, and systemic therapy options. Surgical resection of BrM provides a survival advantage for patients with a single metastasis (8). In modern practice, neurosurgical resection is considered for patients with a limited number of $\mathrm{BrM}$, for larger metastases, for metastases that can be safely resected, when tissue is needed for diagnosis, and when debulking is needed to alleviate symptoms. Historically, patients were treated with whole-brain radiation therapy (WBRT) either alone or after surgical management given the ability for WBRT to extend intracranial progression-free survival (9). However, modern radiation treatments have shifted toward approaches that seek to mitigate the neurocognitive side effects of WBRT, such as hippocampal avoidant WBRT with memantine (10) or stereotactic radiosurgery (SRS) directed only at the BrM without WBRT. This is due to the ability for SRS to mitigate the neurocognitive side effects of WBRT, while providing comparable overall survival and local intracranial control outcomes (albeit at a cost of decreased distant intracranial control) (11). Increasingly, systemic therapies including chemotherapy, targeted therapies, and immunotherapies are applied for BrM patients. The identification of select BrM patients for whom surgery or radiotherapy can be deferred while the patients are treated with systemic therapies is a topic of investigation for many cancer subtypes.

When surgical management is a primary BrM treatment strategy, biomarker analyses of BrM tissues can offer additional clinical gains. Surgical intervention is often indicated for BrM that are $>3 \mathrm{~cm}$, situated in an accessible and/or superficial location, or causing mass effect on the brain (12). Currently, obtaining a tissue biopsy for the primary or sole indication of assessing biomarker information in $\mathrm{BrM}$ is not routinely performed due to associated clinical risks in a patient population with a relatively poor prognosis. Biopsies of BrM, including concurrent biopsies obtained during laser interstitial thermal therapy (LITT) (13), are routinely sent to pathology for diagnostic confirmation and/or differentiation from radiation necrosis. However, these biopsies are rarely sent for broad molecular profiling despite an overall increase in the use of commercial and in-house genomic and transcriptomic sequencing services as part of routine oncology care $(14,15)$.

It has been generally accepted that cancer progression involves somatic clonal evolution (16). Biomarkers identified from primary tumor resections are often assessed years prior to development of BrM and may not reflect emergence of resistance mechanisms that arise during the metastatic process and under treatment pressures. Molecular biomarkers presenting in distant metastases are frequently different from those initially presenting in primary sites. Studies demonstrate that biopsies of other extracranial metastatic sites also do not fully recapitulate the molecular features of $\mathrm{BrM}$-due in part to clonal evolution during neoplasm migration and systemic treatment (16-19). Comparisons of the somatic landscape across visceral metastases may fail to take into account the unique requirements for BrM, such as enabling extravasation through non-fenestrated capillaries, hypoxia-induced neoangiogenesis, and adaptation to the CNS metabolic microenvironment (20). Newer and less invasive techniques for biomarker testing have emerged in recent years (e.g., liquid biopsies). In a recent study, next-generation sequencing of cell-free DNA (cfDNA) from cerebrospinal fluid was shown to be more sensitive than cytologic analysis for diagnosing leptomeningeal disease (21). In the future, cfDNA may be a beneficial tool to detect potential actionable biomarkers in BrM. The use of liquid biopsies to evaluate the response of metastatic tumors to treatment and to provide prognostic information still warrants future investigation (22).

Here, we review the discordance of clinically actionable biomarkers measured in BrM from lung cancer, breast cancer, and melanoma compared to primary sites and extracranial metastases. We discuss these emerging data within the framework of three principal motivations for increased molecular profiling in BrM. First, new treatment targets may be identified as unique actionable mutations emerge in BrM compared to the primary tumor or extracranial metastases. Second, BrM molecular profiling may identify biomarkers of resistance or loss of actionable alterations, thereby excluding ineffective therapies from a treatment plan. Third, new biomarker information in BrM could provide useful prognostic information to aid clinicians and patients in discussing expectations for care.

Obtaining genomic sequencing data on BrM will also help to identify novel drivers that may play a key role in promoting BrM. In a recent report where the authors performed whole-exome sequencing of brain metastases from lung adenocarcinomas (BM-LUAD) and primary lung adenocarcinomas using casecontrol analysis to identify genomic alterations that promote $\mathrm{BrM}$, they identified three regions (MYC, YAP1, MMP13) that had significantly higher amplification frequencies and one region $(C D K N 2 A / B)$ that had higher deletion frequencies in BM-LUAD as compared to primary lung adenocarcinoma (23). Additional 
investigations will be needed to identify driver somatic alterations that promote brain metastases in other types of primary tumors.

While some clinicians may be daunted by the variety and complexity of biomarker testing options available, the impact of this hurdle is rapidly diminishing as "omics" data are increasingly incorporated into oncology practice. However, comprehensive molecular profiling of BrM tissues remains an underutilized option in most health systems, especially outside of dedicated multidisciplinary BrM services. The development of a common understanding among healthcare professionals of the importance of biomarker analysis in BrM will be critical for the development of more effective treatment strategies against BrM and the advancement of precision oncology approaches in this growing patient population.

\section{IDENTIFICATION OF NEW, ACTIONABLE TARGETS}

BrM tissue, obtained through either biopsies or surgical resection during standard care, can provide additional opportunities to identify new targets that were not present in primary tumors and that diverge from paired extracranial metastases. In seminal work on the molecular divergence of BrM, Brastianos et al. observed that more than half of BrM studied harbored at least one potentially actionable biomarker that was not present in the paired primary neoplasm (24). Their data from lung, breast, and renal cell cancers further demonstrated that these alterations were often unique to BrM when compared to lymph node and other extracranial metastases (24). These results have been supported by other recent analyses identifying potentially new and actionable biomarkers in BrM arising from non-small cell lung cancer (NSCLC), breast cancer, and melanoma, described below and summarized in Table 1.

\section{Non-Small Cell Lung Cancer}

Among the various biomarkers associated with lung cancer, genetic alterations in epidermal growth factor receptor (EGFR) are perhaps the most notable biomarker affecting the management of NSCLC patients with BrM. Previous reports have observed a discordance rate of EGFR mutation status between paired BrM and corresponding primary lung tumor samples from $19 \%$ to as high as $67 \%(25,26)$, with BrM typically displaying a higher frequency of EGFR mutations than primary NSCLC tumors (79). Identification of EGFR mutations in BrM presents treatment opportunities, as studies suggest that firstgeneration EGFR tyrosine kinase inhibitors (TKIs), such as gefitinib and erlotinib, have CNS activity (80-83). It is important to note that patients with NSCLC BrM who received erlotinib or gefitinib plus radiotherapy or chemotherapy have exhibited significant intracranial responses and experienced longer progression-free survival (PFS) and median overall survival (OS) compared with patients who received erlotinib or gefitinib alone $(27,28)$. Similar considerations can be entertained for patients receiving the third-generation EGFR TKI osimertinib, which has emerged as an attractive first-line treatment for NSCLC and for NSCLC harboring EGFR Thr790Met (T790M) mutations (29).

Anaplastic lymphoma kinase (ALK) is another notable biomarker in the management of NSCLC patients with BrM $(84,85)$. The most prevalent $A L K$ alteration involves the fusion of $A L K$ with the microtubule-associated protein-like 4 gene (EML4). The fusion event results in the autophosphorylation and constitutive activation of ALK kinase, which contributes to tumorigenesis and progression $(86,87)$. Current data suggest that the concordance for $A L K$ gene fusion between the primary neoplasm site and the matched BrM appears high (33). Knowing the $A L K$ mutation status in BrM is critical, as several drugs exhibiting CNS penetrance, in particular alectinib, brigatinib, and lorlatinib, have been approved by the FDA for the treatment of $A L K$-fusion-positive metastatic NSCLC $(34,35)$. Alectinib, brigatinib, and lorlatinib have all been demonstrated in clinical trials (Alex, ALTA-1L, and Crown) to have superior efficacy to crizotinib in the primary treatment of $A L K$-positive NSCLC (3638). Intracranial response rates in these and other trials indicate that brigatinib and lorlatinib have significant efficacy against $A L K$-positive $\operatorname{BrM}(38,39,88)$, although the effectiveness of these agents on $A L K$-amplified BrM requires further investigation.

Many biomarkers demonstrate a significant rate of concordance between primary tumor sites and BrM. Nevertheless, routine molecular profiling of BrM will help identify possible new actionable biomarkers, especially when there are approved therapeutic options that exhibit good blood-brain barrier permeability, which were recently elegantly reviewed by Soffietti and colleagues (7). These targets include ROS Proto-Oncogene 1 (ROS1), MET Proto-Oncogene (MET) exon 14 skipping mutation, RET Proto-Oncogene (RET), Neurotrophic Receptor Tyrosine Kinase (NTRK), B-Raf ProtoOncogene (BRAF), and KRAS Proto-Oncogene (KRAS). Both crizotinib and entrectinib, multi-targeted TKIs, are now U.S. Food and Drug Administration (FDA)-approved for treatment of NSCLC patients with ROS1-rearranged mutations $(40,43)$. However, as noted above, crizotinib has demonstrated limited intracranial efficacy in the clinic, while studies with entrectinib have reported intracranial response rates of up to 55\% (89). Studies with lorlatinib and ceritinib in ROS1-positive NSCLC have also demonstrated high rates of intracranial response in patients with $\mathrm{BrM}(41,88)$. In a Phase 2, open-label study, approximately $50 \%$ of NSCLC patients with MET exon 14 skipping mutations had some response to treatment with tepotinib and capmatinib $(43,44)$. Both capmatinib and tepotinib are FDA-approved for treatment of patients with MET exon 14 skipping mutant metastatic NSCLC, and recent studies report promising intracranial responses to both agents in patients with this mutation $(44,45)$. Selpercatinib and pralsetinib, two highly selective inhibitors of RET kinase, have been recently approved by the FDA for use in NSCLC patients with RET mutations $(51,52)$ and have both shown robust intracranial activity in patients with $\operatorname{BrM}(53,54)$. KRAS is frequently altered in NSCLC, either through activating 
TABLE 1 | Summary of therapeutic possibilities and prognostic information associated with biomarkers in brain metastases.

\begin{tabular}{|c|c|c|c|c|c|c|}
\hline & $\begin{array}{l}\text { Biomarkers } \\
\text { (types) }\end{array}$ & $\begin{array}{l}\text { Mechanisms } \\
\text { of Actions }\end{array}$ & $\begin{array}{l}\text { Discordance Rates } \\
\text { Between BrM and } \\
\text { Primary And Extracranial } \\
\text { Neoplasm Sites }\end{array}$ & $\begin{array}{l}\text { Therapeutic Options } \\
\text { if Biomarkers Are } \\
\text { Present In BrM }\end{array}$ & $\begin{array}{l}\text { Alternative Therapeutic Options if } \\
\text { Drug Resistance Has Occurred }\end{array}$ & $\begin{array}{l}\text { Associated } \\
\text { Prognostic } \\
\text { Information }\end{array}$ \\
\hline \multirow[t]{6}{*}{ NSCLC } & $\begin{array}{l}\text { EGFR } \\
\text { (mutation) }\end{array}$ & $\begin{array}{l}\text { Receptor } \\
\text { tyrosine kinase }\end{array}$ & $19 \%-66.7 \%(25,26)$ & $\begin{array}{l}\text { TKls: afatinib; erlotinib } \\
\text { or gefitinib + } \\
\text { radiotherapy or } \\
\text { chemotherapy (27-29) }\end{array}$ & $\begin{array}{l}\text { Osimertinib targeting EGFR T790M } \\
(30,31)\end{array}$ & $\begin{array}{l}\uparrow P F S \text { in EGFR- } \\
\text { mutant tumors } \\
\text { treated with icotinib } \\
\text { vs. uncommon } \\
\text { EGFR mutations (32) }\end{array}$ \\
\hline & $\begin{array}{l}\text { ALK } \\
\text { (rearrangement) }\end{array}$ & $\begin{array}{l}\text { Receptor } \\
\text { tyrosine kinase }\end{array}$ & $\begin{array}{l}\text { ALK fusion: rare } \\
\text { ALK amplification w/o } \\
\text { fusion: } 12.5 \%(33)\end{array}$ & $\begin{array}{l}\text { TKls: ceritinib, } \\
\text { alectinib, brigatinib, or } \\
\text { lorlatinib (34-39) }\end{array}$ & & \\
\hline & $\begin{array}{l}\text { ROS1 } \\
\text { (rearrangement) }\end{array}$ & $\begin{array}{l}\text { Receptor } \\
\text { tyrosine kinase }\end{array}$ & $\begin{array}{l}\text { ROS1 fusions enriched in } \\
\text { BrM (26) }\end{array}$ & $\begin{array}{l}\text { TKls: entrectinib, } \\
\text { lorlatinib, ceritinib } \\
(40,41)\end{array}$ & & \\
\hline & $\begin{array}{l}\text { MET (mutation/ } \\
\text { overexpression) }\end{array}$ & $\begin{array}{l}\text { Receptor } \\
\text { tyrosine kinase }\end{array}$ & $\begin{array}{l}\text { Mutations and } \\
\text { amplifications enriched in } \\
\text { BrM (42) }\end{array}$ & $\begin{array}{l}\text { TKls: tepotinib, } \\
\text { capmatinib (43-45) }\end{array}$ & $\begin{array}{l}\text { Possibly contributing to EGFR } \\
\text { treatment resistance; combination } \\
\text { therapies under investigation } \\
(42,46-50)\end{array}$ & \\
\hline & $\begin{array}{l}\text { RET (mutation/ } \\
\text { rearrangement) }\end{array}$ & $\begin{array}{l}\text { Receptor } \\
\text { tyrosine kinase }\end{array}$ & & $\begin{array}{l}\text { TKIs: selpercatinib, } \\
\text { pralsetinib (51-54) }\end{array}$ & & \\
\hline & $\begin{array}{l}\text { KRAS } \\
\text { (overexpression/ } \\
\text { mutation) }\end{array}$ & GTPase & $13 \%(55)$ & $\begin{array}{l}\text { TKls: sotorasib (G12C) } \\
\text { (56) }\end{array}$ & & \\
\hline \multirow[t]{6}{*}{$\begin{array}{l}\text { Breast } \\
\text { cancer }\end{array}$} & $\begin{array}{l}\text { ER/PR } \\
\text { (expression/ } \\
\text { mutation) }\end{array}$ & $\begin{array}{l}\text { Hormone } \\
\text { receptor }\end{array}$ & $\begin{array}{l}\text { ER: } 13.6 \%-29.2 \%(57-59) \\
\text { PR: } 4.2 \%-44.4 \%\end{array}$ & $\begin{array}{l}\text { Endocrine therapy: } \\
\text { tamoxifen }(57,58)\end{array}$ & & \\
\hline & $\begin{array}{l}\text { HER2 } \\
\text { (overexpression/ } \\
\text { mutation) }\end{array}$ & $\begin{array}{l}\text { Receptor } \\
\text { tyrosine kinase }\end{array}$ & $2.3 \%-23.8 \%(57-60)$ & $\begin{array}{l}\text { Anti-HER2: } \\
\text { trastuzumab, } \\
\text { pertuzumab, lapatinib } \\
(14,61) \\
\text { anti-AR: bicalutamide } \\
\text { or enzalutamide } \\
(62,63)\end{array}$ & & $\begin{array}{l}\uparrow \text { OS likely attributed } \\
\text { to treatment effects } \\
\text { (59) }\end{array}$ \\
\hline & PTEN (loss) & $\begin{array}{l}\text { Regulation of } \\
\text { PI3K/AKT/ } \\
\text { mTOR pathway }\end{array}$ & $\begin{array}{l}\text { Loss of PTEN is often seen } \\
\text { in BrM, but is less } \\
\text { commonly seen in } \\
\text { extracranial sites (64-66) }\end{array}$ & $\begin{array}{l}\text { PARP inhibitors: } \\
\text { olaparib, veliparib } \\
(7,67,68)\end{array}$ & $\begin{array}{l}\text { Single-targeting therapies often found } \\
\text { ineffective; combination therapies } \\
\text { currently under investigation (e.g., } \\
\text { HER3+PI3K or PI3K+mTOR) }(69,70)\end{array}$ & $\begin{array}{l}\downarrow \text { time to tumor } \\
\text { recurrence in a } \\
\text { distant site }(63) \\
\downarrow \text { OS in TNBC } \\
\text { subtypes }(71,72)\end{array}$ \\
\hline & $\begin{array}{l}\text { CDK pathway } \\
\text { (mutation/loss) }\end{array}$ & $\begin{array}{l}\text { Serine/threonine } \\
\text { protein kinase; } \\
\text { regulation of } \mathrm{G} 1 \\
\text { checkpoint }\end{array}$ & $\begin{array}{l}\text { Clinically actionable } \\
\text { alterations in the CDK } \\
\text { pathway genes in } 28 \% \text { of } \\
\text { BrM not seen in primaries } \\
\text { (24) }\end{array}$ & $\begin{array}{l}\text { CDK4/6 inhibitors: } \\
\text { abemaciclib, } \\
\text { palbociclib, ribociclib } \\
(24,73,74)\end{array}$ & & \\
\hline & RB1 (loss) & $\begin{array}{l}\text { Regulation of } \\
\text { G1 checkpoint }\end{array}$ & $\begin{array}{l}\text { RB1 loss more commonly } \\
\text { observed in BrM (24) }\end{array}$ & & $\begin{array}{l}\text { May contribute to CDK4/6 inhibitor } \\
\text { treatment resistance }(24,73,74)\end{array}$ & \\
\hline & $\begin{array}{l}\text { HK2 } \\
\text { (overexpression) }\end{array}$ & $\begin{array}{l}\text { Glucose } \\
\text { metabolism }\end{array}$ & & & & $\begin{array}{l}\downarrow \text { post-craniotomy } \\
\text { survival in breast } \\
\text { cancer patients w/ } \\
\text { BrM (75) }\end{array}$ \\
\hline Melanoma & BRAF (mutation) & $\begin{array}{l}\text { Serine-threonine } \\
\text { kinase }\end{array}$ & $7 \%(76,77)$ & $\begin{array}{l}\text { TKls: vemurafenib, } \\
\text { dabrafenib (78) }\end{array}$ & & \\
\hline
\end{tabular}

RTKis, receptor tyrosine kinase inhibitors; OS, overall survival; PFS, progression-free survival.

mutations or through amplification (55). The FDA approved in 2021 the first KRAS inhibitor, sotorasib, which specifically targets the G12C mutant form of KRAS, for metastatic NSCLC. Recent work in matched lung adenocarcinoma primary and BrM tissues reported that KRAS alterations were present in $13 \%$ of BrM tissues that were not present in the matched primary, with enrichment of G12C and G13C mutations (55). Given the potential intracranial efficacy of sotorasib (56) and ongoing trials to address this question, identification of a KRAS G12C mutation in a BrM may provide a potential new avenue for directed therapy in these patients.

\section{Breast Cancer}

Among a host of biomarkers important for the clinical management of breast cancer (BC), estrogen receptor (ER), progesterone receptor (PR), and HER2 are the most crucial. Hormone receptor (HR; ER or PR)-negative, HER2-positive, and triple-negative (TNBC; ER-, PR-, HER2-) statuses are associated 
with increased risk for BCBrM (90). High discordance in these biomarkers exists between primary BC and BrM: ER: 13.6\%29.2\%, PR: $4.2 \%-44.4 \%$, and HER2: $2.3 \%-23.8 \%$ (57-59). In a recent large analysis, this discordance led to subtype switching between primary tumors and BrM in $22.8 \%$ of patients $(91,92)$. Furthermore, pathology and mRNA expression analyses have revealed a downregulation of ER (ESR1) and PR (PGR) gene expression and an upregulation of HER2 (ERBB2) gene expression in BrM, particularly in those arising from TNBC $(19,60,91,92)$.

Since HR and HER2 status are frequently used to determine eligibility for therapeutic options, it is important to analyze BrM tissues to obtain accurate biomarker information for appropriate treatment selection $(58,93)$. Importantly, most patients $(63.6 \%)$ with biomarker discordance between the primary neoplasm and BrM also show discordance between extracranial metastases and $\mathrm{BrM}$, with the primary and extracranial neoplasms typically being concordant $(91,92)$. Thus, different treatment options may have therapeutic activity in BrM that can currently only be identified by profiling BrM. For instance, anti-HER2 therapy (e.g., trastuzumab, pertuzumab, or lapatinib) can be used for HER2 amplification, which are frequently increased in BrM compared to primaries and extracranial metastases. Recently, newer HER2-targeted agents have shown an ability to reach BrM and generate intracranial responses (61). Excitingly, a recent exploratory analysis of 291 patients with BrM who were included in the HER2CLIMB randomized controlled trial demonstrated that the addition of tucatinib to trastuzumab and capecitabine doubled the intracranial response rate, highlighting a regimen that may be especially effective against HER2-positive BrM (14). Similarly, endocrine therapy (e.g., tamoxifen or aromatase inhibitors) can be applied to tumors with positive HR status (94, 95). While treatment options for TNBC BrM have historically been limited to chemotherapy, there is emerging evidence of effectiveness of androgen receptor (AR)-targeted therapies (e.g., bicalutamide or enzalutamide) in TNBC $(62,63)$.

Deletion of phosphatase and tensin homologue (PTEN) on chromosome 10 has been found in a significant portion of BCBrM (96). Furthermore, significantly decreased PTEN mRNA and protein expression has been observed in BCBrM compared to primary tumors $(71,97)$. Loss of PTEN may be a critical factor for BrM development, a possibility that is supported by research suggesting that the loss of PTEN is often exhibited in intracranial malignancies but less commonly in extracranial sites (64-66). Downregulation of PTEN expression has not been observed in bone metastases, suggesting that PTEN dysfunction may be uniquely supportive to metastatic growth in the brain microenvironment (97-99). PTEN antagonizes the phosphatidylinositol 3-kinase (PI3K)/ $\mathrm{AKT} / \mathrm{mTOR}$ pathway, with loss of PTEN resulting in aberrant activation of the pathway and enhanced tumor cell proliferation (100). Identifying PTEN loss in BrM opens the door to potential therapeutic modalities, including PI3K inhibition (7). It has also been suggested that loss of PTEN sensitizes malignant cells to polyadenosine diphosphate ribose polymerase (PARP) inhibition (67). Importantly, BrM profiling could potentially identify resistance mechanisms for PARP inhibitors to help rationally guide the selection of the next line of therapy. Additional therapeutic options targeting loss of PTEN in BrM require further investigation (68).

CDK4/6 inhibitors, including abemaciclib, palbociclib, and ribociclib, are another major class of treatment for BC metastases (7). Abemaciclib is the most brain permeable of the class and has been tested in a recent clinical trial of patients with HR-positive, HER2-negative BrM with promising results (101). Palbociclib has also demonstrated intracranial efficacy in patients with CDK pathway alterations and BrM in a basket trial, including in patients with BrM from breast cancer (102). However, clinical studies have linked homozygous retinoblastoma protein 1 (RB1) loss to resistance to CDK4/6 inhibitors $(24,73,74)$. Homozygous RB1 loss has been observed more frequently in metastatic BC, especially BCBrM, as compared to primary tumor sites (24). RB1 mutations are linked to chromosomal rearrangements that subsequently disrupt genes that inhibit tumor growth and progression. Thus, molecular profiling of BCBrM may present additional treatment options, or may indicate potential resistance to additional options, for these patients.

\section{Melanoma}

$B R A F$ is a gene that encodes the B-Raf protein, which is a serinethreonine kinase. Activating mutations in BRAF, the majority of which are $B R A F^{V 600 E}$, occur in approximately half of cutaneous melanomas (103). Previous studies have reported that up to $7 \%$ of $B R A F$ mutations found in BrM are not found in primary melanoma sites $(76,77)$. Highly selective BRAF and MEK inhibitors (e.g., vemurafenib and dabrafenib) are now approved and demonstrate clinically meaningful activity in the brain (78). These results indicate that biopsies of $\mathrm{BrM}$ for subsequent BRAF analysis should be considered in select patients to guide treatment decisions.

\section{Immune Checkpoint Blockade}

The treatment of patients with a variety of solid tumors has benefitted from immune checkpoint blockade (ICB). While patients with intracranial metastases were historically excluded from systemic and immunotherapy trials, intracranial responses are increasingly observed following ICB, prompting newer interest in harnessing immunotherapy for these patients. In particular, agents targeting the programmed cell death-1 (PD1)/programmed cell death ligand-1 (PD-L1) axis, as well as cytotoxic T-lymphocyte-associated antigen 4 (CTLA-4), have been used clinically now across BrM from a number of primary disease indications and have been approved for use in melanoma and NSCLC $(104,105)$. Most famously, perhaps, dual checkpoint inhibitor therapy with ipilimumab and nivolumab demonstrated intracranial response rates of $52 \%$ in selected asymptomatic patients with active melanoma BrM (106). Overall survival (OS) in this study was $81.5 \%$ at 12 months, and median survival had not been reached at 30 months (106). Meanwhile, an early combined analysis of both lung and melanoma BrM patients from a further phase II study illustrated intracranial response rates to pembrolizumab (antiPD-1) monotherapy of $33 \%$ and $22 \%$, respectively, with nearly 
identical extracranial response rates (107). This may shift the indication for ICB to up front rather than salvage therapy, as a number of these studies were conducted in patients receiving no prior therapy for their intracranial disease, and high concordances between intracranial and extracranial disease were typical.

Despite some notable successes, optimal biomarkers to guide therapeutic decision-making are lacking. Previous studies have reported that up to $50 \%$ of $\mathrm{PD}-1$ expression that was found in BrM was not found in the primary melanoma site (108). This has prompted the search for additional predictive biomarkers for ICB, including tumor mutational burden (TMB). TMB, the total number of non-synonymous mutations in the coding regions of genes, has recently emerged as a potential biomarker to select patients for immunotherapy. The FDA granted accelerated approval to pembrolizumab (KEYTRUDA, Merck \& Co., Inc.) for the treatment of adult and pediatric patients with unresectable or metastatic TMB-high (TMB-H) solid tumors that have progressed following prior treatment and who have no satisfactory alternative treatment options (109). Metastatic tumors have increased TMB at recurrence, and BrM is found to have the highest level of TMB among metastatic sites $(110,111)$. Given emerging evidence of response to ICB in intracranial tumors (112-114), specifically evaluating TMB as a predictive biomarker is a priority that will require increased molecular profiling or BrM.

\section{Radiation Therapy Considerations}

Radiation therapy has long been applied for BrM in a fashion that is largely agnostic to tumor histology. However, emerging evidence suggests that the genetic configuration of BrM could dramatically impact its response to radiation therapy. For instance, a recent pancancer analysis found that tumors containing pathologic genetic alterations in the apical DNA-damage response gene Ataxia telangiectasia mutated (ATM) have dramatically improved local control after radiation therapy compared to control tumors (incidence of irradiated tumor control $13 \%$ vs. $28 \%$ at 2 years) (115). This link between ATM pathogenic variants and radiosensitivity seems to extend to primary brain tumors (116). Thus, the mutational status of genes such as ATM may be one of several factors that, in the setting of a multidisciplinary BrM tumor board, could guide whether to approach a BrM with primary SRS, with surgery, or to reimage the brain following a trial of systemic therapy. Given the discordance between BrM and primary tumor genotype (24), sampling of the BrM ATM genotype would be expected to provide the most robust biomarker for radiosensitivity. Further validation of this finding and investigation of other genetic biomarkers that may be linked to radiosensitivity are warranted in the BrM setting.

\section{IDENTIFICATION OF INEFFECTIVE TREATMENT STRATEGIES}

Molecular profiling of BrM can help indicate whether certain targeted therapies are likely ineffective in this setting. First, resistance to molecularly targeted therapies can occur over the course of treatment and render therapies ineffective against late-stage disease, including BrM. Drug resistance can develop through multiple mechanisms, including but not limited to restoration/reactivation of downstream targets, activation of alternative signaling pathways, and mutations in the binding site of a targeted protein that alter binding of the drug (117). This therapeutic resistance may develop after initial treatments of the primary neoplasm and other metastatic sites. As a result, treatment for BrM based on tissue samples from the primary tumor or other metastatic sites alone may misinform clinical decision-making. Second, actionable targets that were once present in the primary and/or extracranial tumors may be lost in the BrM. Thus, continued treatment with the original matched targeted therapy would be ineffective in the BrM and subject the patient to unnecessary side effects and costs. In this section, we discuss mechanisms of drug resistance and loss of biomarkers in BrM from NSCLC, breast cancer, and melanoma and discuss how knowledge of BrM biomarkers can guide therapy away from ineffective therapies.

\section{Non-Small Cell Lung Cancer}

Although most NSCLC harboring an EGFR mutation are initially responsive to treatment with first-generation TKIs, the majority of patients develop drug resistance within 1-2 years (30). Approximately $60 \%$ of acquired resistance to earlygeneration TKIs is due to the acquiring of the EGFR T790M mutation (118). Tumors may also acquire resistance through activation of signaling molecules downstream of EGFR. Indeed, MET (N-methyl-N'-nitroso-guanidine human osteosarcoma transforming gene), a receptor tyrosine kinase that is considered an oncogenic driver in NSCLC (119-121), is suggested to be closely linked to the EGFR pathway (46-49) and its resistance to inhibitors $(42,50)$, and has been observed to have a higher rate of mutation in BrM versus primary NSCLCs $(69,70)$. Providers treating patients who progress after an EGFR TKI should consider molecular analyses of BrM tissue to confirm whether continued treatment with an EGFR inhibitor, or switching to a different TKI like the T790M mutant-specific, brain-penetrant inhibitor osimertinib (30, 31), will be effective this setting.

\section{Breast Cancer}

As discussed above, activation of the PI3K/AKT/mTOR pathway, such as through loss of PTEN, has been suggested to play a role in the mechanisms underlying poor responses to anti-HER2 therapy in $\mathrm{BC}$ metastases $(122,123)$ and has been found to be altered in more than half of $\mathrm{BCBrM}(122,124)$. However, targeting a single biomarker of the PI3K/AKT/mTOR pathway (e.g., PI3K, HER2, or HER3) is often ineffective $(125,126)$. Combination therapies aimed against multiple molecular targets (e.g., HER3+PI3K or PI3K + mTOR) appear to be more efficacious against BCBrM than monotherapy in preclinical models $(125,126)$.

HR-positive $\mathrm{BC}$ has a lower frequency of metastasizing to the brain compared to other BC subtypes (127). However, in those patients that do develop BrM, their disease has frequently become resistant to hormone therapy at this late stage of the disease through acquisition of HR mutations (7). Furthermore, $\mathrm{BCBrM}$ also frequently demonstrates loss of ER and PR. Indeed, a recent analysis showed that $14.8 \%$ and $22.4 \%$ of BCBrM had 
loss of ER and PR, respectively, contributing to the $22.8 \%$ of cases that had a subtype switch between primary or extracranial tumors and BrM (91, 92). Thus, hormone therapy may be ineffective in treating a significant portion of $\mathrm{BrM}$ given their frequent acquired resistance and/or loss of HR expression.

\section{Melanoma}

Melanoma patients often develop treatment resistance within 1 year of receiving BRAF/MEK-targeted therapy. Agents which target the BRAF/MEK pathway have shown meaningful clinical activity in patients with melanoma BrM, although resistance has been observed to develop within a shorter period of time (78). Several mechanisms for treatment resistance have been suggested, including receptor tyrosine kinase upregulation (e.g., PDGFRß, IGF1R), acquisition of MEK alterations, and activation of the RAS/RAF/MAPK pathway (128).

A recent report comparing melanoma BrM to matched primary and extracranial melanoma tumors demonstrated biomarker discordance between BrM and extracranial sites in 5/8 patients, including loss of mutant NRAS (111). Of note, 2 patients with multiple BrM also showed some differences in potentially actionable alterations between the individual BrM. While overall concordance with extracranial metastases is felt to be high with respect to driver mutations, studies have revealed important molecular differences in melanoma BrM, such as increased activation of the PI3K/AKT pathway (129).

\section{PROGNOSTIC INFORMATION}

Assessing the biomarker status of BrM is not only valuable for informing the treatment plan-both by adding new potential strategies and by ruling out ineffective ones-but can also provide prognostic information to improve patient and provider expectations for care. Prognostic information is particularly important to patients with $\mathrm{BrM}$, as BrM symptoms are often associated with decreased functional status and severe reductions in quality of life.

\section{Non-Small Cell Lung Cancer}

Studies suggest that BrM with driver mutations, including EGFR and ALK, were associated with longer overall survival when treated with surgery, radiosurgery, and non-surgical interventions (5, 130-138). Specifically, Zhou et al. report that BrM patients with common EGFR mutations treated with icotinib exhibited a prolonged PFS compared to those with uncommon EGFR mutations (32). There is a solid body of evidence suggesting that significant survival increases are associated with NSCLC BrM with EGFR mutations compared to those without EGFR mutations (80, 131, 137-139). A recent meta-analysis of 18 studies supports this conclusion and posits that this is likely due to treatment sensitivities of the metastatic lesions (131).

\section{Breast Cancer}

A number of biomarkers hold prognostic value for BCBrM. Approximately $20 \%-25 \%$ of breast cancers have amplified HER2 status (140-142), which is associated with longer survival among
BC patients with BrM (59). Clinical data suggest that increased survival associated with HER2 positivity is likely a reflection of treatment effects related to anti-HER2 therapy rather than a reflection of the HER2-associated biological composition of BrM (59).

As previously discussed, loss of PTEN may be a critical factor for BC metastases to develop in the brain parenchyma (64-66). Studies have shown that loss of PTEN was associated with decreased time to tumor recurrence in distant sites, including the brain, in BC metastases (71). Furthermore, loss of PTEN has been associated with worse overall survival in patients with TNBC $(71,72)$.

Hexokinase (HK2), which plays an essential role in glucose metabolism $(143,144)$, is overexpressed in BrM compared with primary breast tumors. Increased HK2 expression has been associated with decreased post-craniotomy survival in $\mathrm{BC}$ patients with BrM (75).

\section{CHALLENGES AND FUTURE CONSIDERATIONS}

Biomarker analyses of BrM offer potential clinical gains by identifying and/or eliminating candidate targeted therapies. Currently, clinicians do not always obtain biopsies or send resected BrM tissues for biomarker analyses, resulting in a missed opportunity to better inform patient care and potentially improve outcomes. Clinicians may also be daunted by the variety and complexity of biomarker testing options or not be aware of recent work in the genetics of BrM demonstrating biomarker discordance and sometimes unique genetic profile in these metastases. Furthermore, the application of targeted therapies to treatment of $\mathrm{BrM}$ is currently limited to those which can penetrate the blood-tumor/blood-brain barrier, providing an additional layer of complexity in screening potential therapeutic modalities. Providing clinicians access to biomarker testing, clearly summarized and annotated results, and to molecular tumor boards may help them to better appreciate the value and interpret results of biomarker profiling in BrM.

There are at least two potential reasons why clinicians may not seek to test BrM tissues for biomarkers despite the potential utility of this information. First, clinicians may not realize that biomarker analyses from BrM resections or biopsies can provide valuable information that is different from that obtained from the primary tumor or extracranial metastasis sites. Even when clinicians attempt to analyze BrM tissue for biomarkers, a large and growing number of complex testing options can present practical difficulties, particularly in resource-limited settings (145). Wholetranscriptome sequencing (WTS) and whole-exome sequencing (WES) platforms that are currently used for research purposes have recently become standard of care at many institutions and commercial providers. Pan-cancer whole-genome analyses of metastases have revealed therapy-associated mutations that contribute to drug resistance in individual patients (146-148). However, such analyses can be complex to interpret and utilize (149). Furthermore, practical considerations, such as which genetic 
testing platforms are FDA approved, and whether genetic tests are covered by insurance, can make it difficult to recommend additional genomic profiling in BrM. The growing number of testing options, and practical considerations for each, makes it increasingly difficult for clinicians to order and select the most appropriate biomarker analyses. In the future, development of targeted panels for types of primary tumors that metastasize to the brain could be considered to augment accessibility of BrM biomarker analyses for clinicians.

The optimal use of targeted BrM therapies depends largely on the expertise of clinicians (150), many of whom have limited experience considering the efficacy of targeted therapies in crossing the blood-brain barrier (151). As a result, management of BrM often requires a multidisciplinary approach (12), with molecular tumor boards being a vital venue for discussion of treatment plans with input from multiple specialties (152). Access to molecular tumor boards would likely improve and increase the application of genomically guided cancer care for patients with $\mathrm{BrM}$, including targeted clinical trial enrollment. Data suggest that less than half of all hospitals and only $5 \%$ of non-academic hospitals have access to molecular tumor boards (149). Clinicians at hospitals treating patients with BrM may face logistical obstacles in accessing molecular tumor boards, such as long distances to in-person meetings, low local patient volume, and limited personnel, although the recent global shift toward increasing comfort with web-based conferencing may serve to accelerate adoption of online multidisciplinary tumor boards. Organizing molecular tumor boards across multiple hospitals or hospital systems to provide clinicians access to relevant expertise is a logical and critical step forward in advancing use of molecular tumor boards across sites (149).

\section{CONCLUSION}

Targeted therapeutic strategies and prognostic stratifications for treatment of patients with BrM are increasingly common.

\section{REFERENCES}

1. Davis FG, Dolecek TA, McCarthy BJ, Villano JL. Toward Determining the Lifetime Occurrence of Metastatic Brain Tumors Estimated From 2007 United States Cancer Incidence Data. Neuro Oncol (2012) 14(9):1171-7. doi: 10.1093/neuonc/nos152

2. Nathoo N, Chahlavi A, Barnett GH, Toms SA. Pathobiology of Brain Metastases. J Clin Pathol (2005) 58(3):237-42. doi: 10.1136/jcp.2003.013623

3. Fox BD, Cheung VJ, Patel AJ, Suki D, Rao G. Epidemiology of Metastatic Brain Tumors. Neurosurg Clin NAm (2011) 22(1):1-6. doi: 10.1016/j.nec.2010.08.007

4. Fecci PE, Champion CD, Hoj J, McKernan CM, Goodwin CR, Kirkpatrick JP, et al. The Evolving Modern Management of Brain Metastasis. Clin Cancer Res an Off J Am Assoc Cancer Res (2019) 25(22):6570-80. doi: 10.1158/1078-0432.CCR-18-1624

5. Sperduto PW, Yang TJ, Beal K, Pan H, Brown PD, Bangdiwala A, et al. Estimating Survival in Patients With Lung Cancer and Brain Metastases: An Update of the Graded Prognostic Assessment for Lung Cancer Using Molecular Markers (Lung-molGPA). JAMA Oncol (2017) 3(6):827-31. doi: 10.1001/jamaoncol.2016.3834

6. Stelzer KJ. Epidemiology and Prognosis of Brain Metastases. Surg Neurol Int (2013) 4(Suppl 4):S192-202. doi: 10.4103/2152-7806.111296
Despite the fact that discordance often exists between BrM and both primary tumors and distant extracranial metastases, molecular profiling of resected BrM is not currently routine, and biopsies for the purpose of biomarker evaluation are rare. Biomarker information from BrM can identify new mutations with viable targeted therapies, eliminate agents from consideration when resistance or loss of actionable biomarkers has developed in the BrM, and improve prognostication. Clinicians may be initially dismayed by the variety and complexity of biomarker testing options, but this challenge can be overcome by (virtual) molecular-tumor boards to guide decision-making and advance personalized oncology care for patients with BrM.

\section{AUTHOR CONTRIBUTIONS}

Investigation: ES. Resources: KW, CRG. Data curation: ES, AV. Writing: ES, AV, MP, KB, RV, CB, BP, ZR, AS, JC, CA, PF, CRG, KW. Visualization: ES. Supervision: CRG, KW. Project administration: CRG, KW. All authors contributed to the article and approved the submitted version.

\section{FUNDING}

CRG received grants from the Robert Wood Johnson Harold Amos Medical Faculty Development Program, Federal Food and Drug Administration, and the NIH/NINDS K12 NRCDP Physician Scientist Award. CA is a Translating Duke Health Scholar of Duke University, Durham, NC. ZR received a Pediatric Brain Tumor Foundation Early Career Development Award, a Defeat DIPG SoSo Strong Foundation ChadThough Foundation New Investigator Award, a St. Baldrick's Foundation Fellowship, and developmental funds from Cancer Center Support Grant P30CA014236.

7. Soffietti R, Ahluwalia M, Lin N, Ruda R. Management of Brain Metastases According to Molecular Subtypes. Nat Rev Neurol (2020) 16(10):557-74. doi: 10.1038/s41582-020-0391-x

8. Patchell RA, Tibbs PA, Walsh JW, Dempsey RJ, Maruyama Y, Kryscio RJ, et al. A Randomized Trial of Surgery in the Treatment of Single Metastases to the Brain. N Engl J Med (1990) 322(8):494-500. doi: 10.1056/ NEJM199002223220802

9. Patchell RA, Tibbs PA, Regine WF, Dempsey RJ, Mohiuddin M, Kryscio RJ, et al. Postoperative Radiotherapy in the Treatment of Single Metastases to the Brain: A Randomized Trial. JAMA (1998) 280(17):1485-9. doi: 10.1001/ jama.280.17.1485

10. Brown PD, Gondi V, Pugh S, Tome WA, Wefel JS, Armstrong TS, et al. Hippocampal Avoidance During Whole-Brain Radiotherapy Plus Memantine for Patients With Brain Metastases: Phase III Trial NRG Oncology Cc001. J Clin Oncol (2020) 38(10):1019-29. doi: 10.1200/ JCO.19.02767

11. Brown PD, Jaeckle K, Ballman KV, Farace E, Cerhan JH, Anderson SK, et al. Effect of Radiosurgery Alone vs Radiosurgery With Whole Brain Radiation Therapy on Cognitive Function in Patients With 1 to 3 Brain Metastases: A Randomized Clinical Trial. JAMA (2016) 316(4):401-9. doi: 10.1001/ jama.2016.9839 
12. Moravan MJ, Fecci PE, Anders CK, Clarke JM, Salama AKS, Adamson JD, et al. Current Multidisciplinary Management of Brain Metastases. Cancer (2020) 126(7):1390-406. doi: 10.1002/cncr.32714

13. Holste KG, Orringer DA. Laser Interstitial Thermal Therapy. Neurooncol $A d v$ (2020) 2(1):vdz035. doi: 10.1093/noajnl/vdz035

14. Lin NU, Borges V, Anders C, Murthy RK, Paplomata E, Hamilton E, et al. Intracranial Efficacy and Survival With Tucatinib Plus Trastuzumab and Capecitabine for Previously Treated HER2-Positive Breast Cancer With Brain Metastases in the HER2CLIMB Trial. J Clin Oncol (2020) 38 (23):2610-9. doi: 10.1200/JCO.20.00775

15. Conway JR, Warner JL, Rubinstein WS, Miller RS. Next-Generation Sequencing and the Clinical Oncology Workflow: Data Challenges, Proposed Solutions, and a Call to Action. JCO Precis Oncol (2019) 3: PO.19.00232. doi: 10.1200/PO.19.00232

16. Scott J, Marusyk A. Somatic Clonal Evolution: A Selection-Centric Perspective. Biochim Biophys Acta Rev Cancer (2017) 1867(2):139-50. doi: 10.1016/j.bbcan.2017.01.006

17. Yachida S, Jones S, Bozic I, Antal T, Leary R, Fu B, et al. Distant Metastasis Occurs Late During the Genetic Evolution of Pancreatic Cancer. Nature (2010) 467(7319):1114-7. doi: 10.1038/nature09515

18. El-Deiry WS, Vijayvergia N, Xiu J, Scicchitano A, Lim B, Yee NS, et al. Molecular Profiling of 6,892 Colorectal Cancer Samples Suggests Different Possible Treatment Options Specific to Metastatic Sites. Cancer Biol Ther (2015) 16(12):1726-37. doi: 10.1080/15384047.2015.1113356

19. Stefanovic S, Wirtz R, Deutsch TM, Hartkopf A, Sinn P, Varga Z, et al. Tumor Biomarker Conversion Between Primary and Metastatic Breast Cancer: mRNA Assessment and Its Concordance With Immunohistochemistry. Oncotarget (2017) 8(31):51416-28. doi: 10.18632/ oncotarget.18006

20. Tabouret E, Bauchet L, Carpentier AF. Brain Metastases Epidemiology and Biology. Bull Cancer (2013) 100(1):57-62. doi: 10.1684/bdc.2012.1681

21. White MD, Klein RH, Shaw B, Kim A, Subramanian M, Mora JL, et al. Detection of Leptomeningeal Disease Using Cell-Free DNA From Cerebrospinal Fluid. JAMA Netw Open (2021) 4(8):e2120040. doi: 10.1001/jamanetworkopen.2021.20040

22. Yan W, Xu T, Zhu H, Yu J. Clinical Applications of Cerebrospinal Fluid Circulating Tumor DNA as a Liquid Biopsy for Central Nervous System Tumors. Onco Targets Ther (2020) 13:719-31. doi: 10.2147/OTT.S229562

23. Shih DJH, Nayyar N, Bihun I, Dagogo-Jack I, Gill CM, Aquilanti E, et al. Genomic Characterization of Human Brain Metastases Identifies Drivers of Metastatic Lung Adenocarcinoma. Nat Genet (2020) 52(4):371-7. doi: 10.1038/s41588-020-0592-7

24. Brastianos PK, Carter SL, Santagata S, Cahill DP, Taylor-Weiner A, Jones RT, et al. Genomic Characterization of Brain Metastases Reveals Branched Evolution and Potential Therapeutic Targets. Cancer Discov (2015) 5 (11):1164-77. doi: 10.1158/2159-8290.CD-15-0369

25. Sherwood J, Dearden S, Ratcliffe M, Walker J. Mutation Status Concordance Between Primary Lesions and Metastatic Sites of Advanced non-Small-Cell Lung Cancer and the Impact of Mutation Testing Methodologies: A Literature Review. J Exp Clin Cancer Res (2015) 34:92. doi: 10.1186/ s13046-015-0207-9

26. Li D, Huang Y, Cai L, Wu M, Bao H, Xu Y, et al. Genomic Landscape of Metastatic Lung Adenocarcinomas From Large-Scale Clinical Sequencing. Neoplasia (2021) 23(12):1204-12. doi: 10.1016/j.neo.2021.10.001

27. Stewart DJ, Erasmus JJ. Erlotinib Accumulation in Brain Metastases From non-Small Cell Lung Cancer: Visualization by Positron Emission Tomography in a Patient Harboring a Mutation in the Epidermal Growth Factor Receptor. J Thorac Oncol (2011) 6(7):1149-51. doi: 10.1097/ JTO.0b013e318223931f

28. Maemondo M, Inoue A, Kobayashi K, Sugawara S, Oizumi S, Isobe H, et al. Gefitinib or Chemotherapy for Non-Small-Cell Lung Cancer With Mutated EGFR. N Engl J Med (2010) 362(25):2380-8. doi: 10.1056/NEJMoa0909530

29. Wu YL, Tsuboi M, He J, John T, Grohe C, Majem M, et al. Osimertinib in Resected EGFR-Mutated Non-Small-Cell Lung Cancer. N Engl J Med (2020) 383(18):1711-23. doi: 10.1056/NEJMoa2027071

30. Janne PA, Yang JC, Kim DW, Planchard D, Ohe Y, Ramalingam SS, et al. AZD9291 in EGFR Inhibitor-Resistant Non-Small-Cell Lung Cancer. N Engl J Med (2015) 372(18):1689-99. doi: 10.1056/NEJMoa1411817
31. Ballard P, Yates JW, Yang Z, Kim DW, Yang JC, Cantarini M, et al. Preclinical Comparison of Osimertinib With Other EGFR-TKIs in EGFRMutant NSCLC Brain Metastases Models, and Early Evidence of Clinical Brain Metastases Activity. Clin Cancer Res an Off J Am Assoc Cancer Res (2016) 22(20):5130-40. doi: 10.1158/1078-0432.CCR-16-0399

32. Zhou S, Hu X, Wang Y, Junling L, Zhou L, Hao X, et al. Effectiveness of Icotinib Against non-Small-Cell Lung Cancer With Uncommon EGFR Mutations. J Clin Oncol (2018) 36(15_suppl):e21083-e. doi: 10.1200/ JCO.2018.36.15_suppl.e21083

33. Preusser M, Berghoff AS, Ilhan-Mutlu A, Magerle M, Dinhof C, Widhalm G, et al. ALK Gene Translocations and Amplifications in Brain Metastases of non-Small Cell Lung Cancer. Lung Cancer (2013) 80(3):278-83. doi: 10.1016/j.lungcan.2013.01.019

34. Han CH, Brastianos PK. Genetic Characterization of Brain Metastases in the Era of Targeted Therapy. Front Oncol (2017) 7:230. doi: 10.3389/ fonc. 2017.00230

35. Klempner SJ, Ou SH. Anaplastic Lymphoma Kinase Inhibitors in Brain Metastases From ALK+ Non-Small Cell Lung Cancer: Hitting the Target Even in the CNS. Chin Clin Oncol (2015) 4(2):20. doi: 10.3978/j.issn.23043865.2015.05.03

36. Peters S, Camidge DR, Shaw AT, Gadgeel S, Ahn JS, Kim DW, et al. Alectinib Versus Crizotinib in Untreated ALK-Positive Non-Small-Cell Lung Cancer. N Engl J Med (2017) 377(9):829-38. doi: 10.1056/NEJMoa1704795

37. Camidge DR, Kim HR, Ahn MJ, Yang JCH, Han JY, Hochmair MJ, et al. Brigatinib Versus Crizotinib in Advanced ALK Inhibitor-Naive ALKPositive Non-Small Cell Lung Cancer: Second Interim Analysis of the Phase III ALTA-11 Trial. J Clin Oncol (2020) 38(31):3592-603. doi: 10.1200/JCO.20.00505

38. Shaw AT, Bauer TM, de Marinis F, Felip E, Goto Y, Liu G, et al. First-Line Lorlatinib or Crizotinib in Advanced ALK-Positive Lung Cancer. New Engl J Med (2020) 383(21):2018-29. doi: 10.1056/NEJMoa2027187

39. Ceddia S, Codacci-Pisanelli G. Treatment of Brain Metastases in ALKPositive Non-Small Cell Lung Cancer. Crit Rev Oncol Hematol (2021) 165:103400. doi: 10.1016/j.critrevonc.2021.103400

40. Sehgal K, Piper-Vallillo AJ, Viray H, Khan AM, Rangachari D, Costa DB. Cases of ROS1-Rearranged Lung Cancer: When to Use Crizotinib, Entrectinib, Lorlatinib, and Beyond? Precis Cancer Med (2020) 3:17. doi: 10.21037/pcm-2020-potb-02

41. Lim SM, Kim HR, Lee JS, Lee KH, Lee YG, Min YJ, et al. Open-Label, Multicenter, Phase II Study of Ceritinib in Patients With Non-Small-Cell Lung Cancer Harboring ROS1 Rearrangement. J Clin Oncol (2017) 35 (23):2613-8. doi: 10.1200/JCO.2016.71.3701

42. Benedettini E, Sholl LM, Peyton M, Reilly J, Ware C, Davis L, et al. Met Activation in Non-Small Cell Lung Cancer Is Associated With De Novo Resistance to EGFR Inhibitors and the Development of Brain Metastasis. Am J Pathol (2010) 177(1):415-23. doi: 10.2353/ajpath.2010.090863

43. Paik PK, Felip E, Veillon R, Sakai H, Cortot AB, Garassino MC, et al. Tepotinib in Non-Small-Cell Lung Cancer With MET Exon 14 Skipping Mutations. N Engl J Med (2020) 383(10):931-43. doi: 10.1056/ NEJMoa2004407

44. Wolf J, Seto T, Han JY, Reguart N, Garon EB, Groen HJM, et al. Capmatinib in MET Exon 14-Mutated or MET-Amplified Non-Small-Cell Lung Cancer. New Engl J Med (2020) 383(10):944-57. doi: 10.1056/NEJMoa2002787

45. Patel JD, Le X, Veillon R, Anderson IC, Bestvina CM, Demedts I, et al. Intracranial Activity of Tepotinib in Patients (Pts) With MET Exon 14 (METex14) Skipping NSCLC Enrolled in VISION. J Clin Oncol (2021) 39 (15_suppl):9084-. doi: 10.1200/JCO.2021.39.15_suppl.9084

46. Agarwal S, Zerillo C, Kolmakova J, Christensen JG, Harris LN, Rimm DL, et al. Association of Constitutively Activated Hepatocyte Growth Factor Receptor (Met) With Resistance to a Dual EGFR/Her2 Inhibitor in nonSmall-Cell Lung Cancer Cells. Br J Cancer (2009) 100(6):941-9. doi: 10.1038/ sj.bjc. 6604937

47. Breindel JL, Haskins JW, Cowell EP, Zhao M, Nguyen DX, Stern DF. EGF Receptor Activates MET Through MAPK to Enhance Non-Small Cell Lung Carcinoma Invasion and Brain Metastasis. Cancer Res (2013) 73(16):505365. doi: 10.1158/0008-5472.CAN-12-3775

48. McDermott U, Pusapati RV, Christensen JG, Gray NS, Settleman J. Acquired Resistance of non-Small Cell Lung Cancer Cells to MET Kinase Inhibition is 
Mediated by a Switch to Epidermal Growth Factor Receptor Dependency. Cancer Res (2010) 70(4):1625-34. doi: 10.1158/0008-5472.CAN-09-3620

49. Mueller KL, Yang ZQ, Haddad R, Ethier SP, Boerner JL. EGFR/Met Association Regulates EGFR TKI Resistance in Breast Cancer. $J$ Mol Signal (2010) 5:8. doi: 10.1186/1750-2187-5-8

50. Engelman JA, Zejnullahu K, Mitsudomi T, Song Y, Hyland C, Park JO, et al. MET Amplification Leads to Gefitinib Resistance in Lung Cancer by Activating ERBB3 Signaling. Science (2007) 316(5827):1039-43. doi: 10.1126/science. 1141478

51. Subbiah V, Shen T, Terzyan SS, Liu X, Hu X, Patel KP, et al. Structural Basis of Acquired Resistance to Selpercatinib and Pralsetinib Mediated by nonGatekeeper RET Mutations. Ann Oncol Off J Eur Soc Med Oncol (2021) 32 (2):261-8. doi: 10.1016/j.annonc.2020.10.599

52. Drusbosky LM, Rodriguez E, Dawar R, Ikpeazu CV. Therapeutic Strategies in RET Gene Rearranged Non-Small Cell Lung Cancer. J Hematol Oncol (2021) 14(1):50. doi: 10.1186/s13045-021-01063-9

53. Subbiah V, Gainor JF, Oxnard GR, Tan DSW, Owen DH, Cho BC, et al. Intracranial Efficacy of Selpercatinib in RET Fusion-Positive Non-Small Cell Lung Cancers on the LIBRETTO-001 Trial. Clin Cancer Res an Off J Am Assoc Cancer Res (2021) 27(15):4160-7. doi: 10.1158/1078-0432.CCR-21-0800

54. Gainor JF, Curigliano G, Kim DW, Lee DH, Besse B, Baik CS, et al. Pralsetinib for RET Fusion-Positive Non-Small-Cell Lung Cancer (ARROW): A Multi-Cohort, Open-Label, Phase 1/2 Study. Lancet Oncol (2021) 22(7):959-69. doi: 10.1016/S1470-2045(21)00247-3

55. Vassella E, Kashani E, Zens P, Kundig A, Fung C, Scherz A, et al. Mutational Profiles of Primary Pulmonary Adenocarcinoma and Paired Brain Metastases Disclose the Importance of KRAS Mutations. Eur J Cancer (2021) 159:227-36. doi: 10.1016/j.ejca.2021.10.006

56. Ramalingam S, Skoulidis F, Govindan R, Velcheti V, Li B, Besse B, et al. P52.03 Efficacy of Sotorasib in KRAS P.G12C-Mutated NSCLC With Stable Brain Metastases: A Post-Hoc Analysis of CodeBreaK 100. J Thorac Oncol (2021) 16(10, Supplement):S1123. doi: 10.1016/j.jtho.2021.08.547

57. Jung J, Lee SH, Park M, Youn JH, Shin SH, Gwak HS, et al. Discordances in ER, PR, and HER2 Between Primary Breast Cancer and Brain Metastasis. J Neurooncol (2018) 137(2):295-302. doi: 10.1007/s11060-017-2717-0

58. Amir E, Miller N, Geddie W, Freedman O, Kassam F, Simmons C, et al. Prospective Study Evaluating the Impact of Tissue Confirmation of Metastatic Disease in Patients With Breast Cancer. J Clin Oncol (2012) 30 (6):587-92. doi: 10.1200/JCO.2010.33.5232

59. Shen Q, Sahin AA, Hess KR, Suki D, Aldape KD, Sawaya R, et al. Breast Cancer With Brain Metastases: Clinicopathologic Features, Survival, and Paired Biomarker Analysis. Oncologist (2015) 20(5):466-73. doi: 10.1634/ theoncologist.2014-0107

60. Priedigkeit N, Hartmaier RJ, Chen Y, Vareslija D, Basudan A, Watters RJ, et al. Intrinsic Subtype Switching and Acquired ERBB2/HER2 Amplifications and Mutations in Breast Cancer Brain Metastases. JAMA Oncol (2017) 3(5):666-71. doi: 10.1001/jamaoncol.2016.5630

61. Zimmer AS, Van Swearingen AED, Anders CK. HER2-Positive Breast Cancer Brain Metastasis: A New and Exciting Landscape. Cancer Rep (Hoboken) (2020) e1274. doi: 10.1002/cnr2.1274

62. Foulkes WD, Smith IE, Reis-Filho JS. Triple-Negative Breast Cancer. N Engl J Med (2010) 363(20):1938-48. doi: 10.1056/NEJMra1001389

63. Giovannelli P, Di Donato M, Galasso G, Di Zazzo E, Bilancio A, Migliaccio A. The Androgen Receptor in Breast Cancer. Front Endocrinol (Lausanne) (2018) 9:492. doi: 10.3389/fendo.2018.00492

64. De Witt Hamer PC, Leenstra S, Van Noorden CJ, Zwinderman AH. Organotypic Glioma Spheroids for Screening of Experimental Therapies: How Many Spheroids and Sections are Required? Cytometry A (2009) 75 (6):528-34. doi: 10.1002/cyto.a.20716

65. Lamszus K. Meningioma Pathology, Genetics, and Biology. J Neuropathol Exp Neurol (2004) 63(4):275-86. doi: 10.1093/jnen/63.4.275

66. Ohgaki H, Kleihues P. Genetic Alterations and Signaling Pathways in the Evolution of Gliomas. Cancer Sci (2009) 100(12):2235-41. doi: 10.1111/ j.1349-7006.2009.01308.x

67. Mendes-Pereira AM, Martin SA, Brough R, McCarthy A, Taylor JR, Kim JS, et al. Synthetic Lethal Targeting of PTEN Mutant Cells With PARP Inhibitors. EMBO Mol Med (2009) 1(6-7):315-22. doi: 10.1002/ emmm.200900041
68. Lee EK, Matulonis UA. PARP Inhibitor Resistance Mechanisms and Implications for Post-Progression Combination Therapies. Cancers (Basel) (2020) 12(8):2054. doi: 10.3390/cancers12082054

69. Milan M, Benvenuti S, Balderacchi AM, Virzi AR, Gentile A, Senetta R, et al. RON Tyrosine Kinase Mutations in Brain Metastases From Lung Cancer. ERJ Open Res (2018) 4(1):00083-2017. doi: 10.1183/23120541.00083-2017

70. Stella GM, Senetta R, Inghilleri S, Verdun di Cantogno L, Mantovani C, Piloni D, et al. MET Mutations Are Associated With Aggressive and Radioresistant Brain Metastatic Non-Small-Cell Lung Cancer. Neuro Oncol (2016) 18(4):598-9. doi: 10.1093/neuonc/nov325

71. Adamo B, Deal AM, Burrows E, Geradts J, Hamilton E, Blackwell KL, et al. Phosphatidylinositol 3-Kinase Pathway Activation in Breast Cancer Brain Metastases. Breast Cancer Res (2011) 13(6):R125. doi: 10.1186/bcr3071

72. Carbognin L, Miglietta F, Paris I, Dieci MV. Prognostic and Predictive Implications of PTEN in Breast Cancer: Unfulfilled Promises But Intriguing Perspectives. Cancers (Basel) (2019) 11(9):1401. doi: 10.3390/cancers11091401

73. Fry DW, Harvey PJ, Keller PR, Elliott WL, Meade M, Trachet E, et al. Specific Inhibition of Cyclin-Dependent Kinase 4/6 by PD 0332991 and Associated Antitumor Activity in Human Tumor Xenografts. Mol Cancer Ther (2004) 3(11):1427-38.

74. Condorelli R, Spring L, O'Shaughnessy J, Lacroix L, Bailleux C, Scott V, et al. Polyclonal RB1 Mutations and Acquired Resistance to CDK 4/6 Inhibitors in Patients With Metastatic Breast Cancer. Ann Oncol Off J Eur Soc Med Oncol (2018) 29(3):640-5. doi: 10.1093/annonc/mdx784

75. Palmieri D, Fitzgerald D, Shreeve SM, Hua E, Bronder JL, Weil RJ, et al. Analyses of Resected Human Brain Metastases of Breast Cancer Reveal the Association Between Up-Regulation of Hexokinase 2 and Poor Prognosis. Mol Cancer Res (2009) 7(9):1438-45. doi: 10.1158/1541-7786.MCR-09-0234

76. Valachis A, Ullenhag GJ. Discrepancy in BRAF Status Among Patients With Metastatic Malignant Melanoma: A Meta-Analysis. Eur J Cancer (2017) 81:106-15. doi: 10.1016/j.ejca.2017.05.015

77. Hannan EJ, O'Leary DP, MacNally SP, Kay EW, Farrell MA, Morris PG, et al. The Significance of BRAF V600E Mutation Status Discordance Between Primary Cutaneous Melanoma and Brain Metastases: The Implications for BRAF Inhibitor Therapy. Med (Baltimore) (2017) 96(48): e8404. doi: 10.1097/MD.0000000000008404

78. Davies MA, Saiag P, Robert C, Grob JJ, Flaherty KT, Arance A, et al. Dabrafenib Plus Trametinib in Patients With BRAF(V600)-Mutant Melanoma Brain Metastases (COMBI-MB): A Multicentre, Multicohort, Open-Label, Phase 2 Trial. Lancet Oncol (2017) 18(7):863-73. doi: 10.1016/ S1470-2045(17)30429-1

79. Berghoff AS, Bartsch R, Wohrer A, Streubel B, Birner P, Kros JM, et al. Predictive Molecular Markers in Metastases to the Central Nervous System: Recent Advances and Future Avenues. Acta Neuropathol (2014) 128(6):87991. doi: 10.1007/s00401-014-1350-7

80. Park SJ, Kim HT, Lee DH, Kim KP, Kim SW, Suh C, et al. Efficacy of Epidermal Growth Factor Receptor Tyrosine Kinase Inhibitors for Brain Metastasis in Non-Small Cell Lung Cancer Patients Harboring Either Exon 19 or 21 Mutation. Lung Cancer (2012) 77(3):556-60. doi: 10.1016/ j.lungcan.2012.05.092

81. Wu YL, Lee JS, Thongprasert S, Yu CJ, Zhang L, Ladrera G, et al. Intercalated Combination of Chemotherapy and Erlotinib for Patients With Advanced Stage Non-Small-Cell Lung Cancer (FASTACT-2): A Randomised, DoubleBlind Trial. Lancet Oncol (2013) 14(8):777-86. doi: 10.1016/S1470-2045(13) 70254-7

82. Tan L, Wu Y, Ma X, Yan Y, Shao S, Liu J, et al. A Comprehensive MetaAnalysis of Association Between EGFR Mutation Status and Brain Metastases in NSCLC. Pathol Oncol Res (2019) 25(2):791-9. doi: 10.1007/ s12253-019-00598-0

83. Ceresoli GL. Role of EGFR Inhibitors in the Treatment of Central Nervous System Metastases From Non-Small Cell Lung Cancer. Curr Cancer Drug Targets (2012) 12(3):237-46. doi: 10.2174/156800912799277430

84. Petrelli F, Lazzari C, Ardito R, Borgonovo K, Bulotta A, Conti B, et al. Efficacy of ALK Inhibitors on NSCLC Brain Metastases: A Systematic Review and Pooled Analysis of 21 Studies. PloS One (2018) 13(7): e0201425. doi: 10.1371/journal.pone.0201425

85. Rangachari D, Yamaguchi N, VanderLaan PA, Folch E, Mahadevan A, Floyd SR, et al. Brain Metastases in Patients With EGFR-Mutated or ALK- 
Rearranged Non-Small-Cell Lung Cancers. Lung Cancer (2015) 88(1):10811. doi: 10.1016/j.lungcan.2015.01.020

86. Ducray SP, Natarajan K, Garland GD, Turner SD, Egger G. The Transcriptional Roles of ALK Fusion Proteins in Tumorigenesis. Cancers (Basel) (2019) 11(8):1074. doi: 10.3390/cancers11081074

87. Palmer RH, Vernersson E, Grabbe C, Hallberg B. Anaplastic Lymphoma Kinase: Signalling in Development and Disease. Biochem J (2009) 420 (3):345-61. doi: 10.1042/BJ20090387

88. Naito T, Shiraishi H, Fujiwara Y. Brigatinib and Lorlatinib: Their Effect on ALK Inhibitors in NSCLC Focusing on Resistant Mutations and Central Nervous System Metastases. Jpn J Clin Oncol (2021) 51(1):37-44. doi: 10.1093/jjco/hyaa192

89. Drilon A, Siena S, Dziadziuszko R, Barlesi F, Krebs MG, Shaw AT, et al. Entrectinib in ROS1 Fusion-Positive Non-Small-Cell Lung Cancer: Integrated Analysis of Three Phase 1-2 Trials. Lancet Oncol (2020) 21 (2):261-70. doi: 10.1016/S1470-2045(19)30690-4

90. Lin NU, Bellon JR, Winer EP. CNS Metastases in Breast Cancer. J Clin Oncol (2004) 22(17):3608-17. doi: 10.1200/JCO.2004.01.175

91. Hulsbergen AFC, Claes A, Kavouridis VK, Ansaripour A, Nogarede C, Hughes ME, et al. Subtype Switching in Breast Cancer Brain Metastases: A Multicenter Analysis. Neuro Oncol (2020) 22(8):1173-81. doi: 10.1093/ neuonc/noaa013

92. Sammons S, Van Swearingen AED, Anders CK. Receptor Discordance in Breast Cancer Brain Metastases: When Knowledge Is Power. Neuro Oncol (2020) 22(8):1060-1. doi: 10.1093/neuonc/noaal31

93. Thompson AM, Jordan LB, Quinlan P, Anderson E, Skene A, Dewar JA, et al. Prospective Comparison of Switches in Biomarker Status Between Primary and Recurrent Breast Cancer: The Breast Recurrence In Tissues Study (BRITS). Breast Cancer Res (2010) 12(6):R92. doi: 10.1186/bcr2771

94. Salkeni MA, Hall SJ. Metastatic Breast Cancer: Endocrine Therapy Landscape Reshaped. Avicenna J Med (2017) 7(4):144-52. doi: 10.4103/ ajm.AJM_20_17

95. Lien EA, Wester K, Lonning PE, Solheim E, Ueland PM. Distribution of Tamoxifen and Metabolites Into Brain Tissue and Brain Metastases in Breast Cancer Patients. Br J Cancer (1991) 63(4):641-5. doi: 10.1038/bjc.1991.147

96. Hohensee I, Lamszus K, Riethdorf S, Meyer-Staeckling S, Glatzel M, Matschke J, et al. Frequent Genetic Alterations in EGFR- and HER2Driven Pathways in Breast Cancer Brain Metastases. Am J Pathol (2013) 183(1):83-95. doi: 10.1016/j.ajpath.2013.03.023

97. Wikman H, Lamszus K, Detels N, Uslar L, Wrage M, Benner C, et al. Relevance of PTEN Loss in Brain Metastasis Formation in Breast Cancer Patients. Breast Cancer Res (2012) 14(2):R49. doi: 10.1186/bcr3150

98. Pantel K, Brakenhoff RH. Dissecting the Metastatic Cascade. Nat Rev Cancer (2004) 4(6):448-56. doi: 10.1038/nrc1370

99. Bos PD, Zhang XH, Nadal C, Shu W, Gomis RR, Nguyen DX, et al. Genes That Mediate Breast Cancer Metastasis to the Brain. Nature (2009) 459 (7249):1005-9. doi: 10.1038/nature08021

100. Dillon LM, Miller TW. Therapeutic Targeting of Cancers With Loss of PTEN Function. Curr Drug Targets (2014) 15(1):65-79. doi: 10.2174/ 1389450114666140106100909

101. Nguyen LV, Searle K, Jerzak KJ. Central Nervous System-Specific Efficacy of CDK4/6 Inhibitors in Randomized Controlled Trials for Metastatic Breast Cancer. Oncotarget (2019) 10(59):6317-22. doi: 10.18632/oncotarget.27238

102. Brastianos PK, Kim AE, Wang N, Lee EQ, Ligibel J, Cohen JV, et al. Palbociclib Demonstrates Intracranial Activity in Progressive Brain Metastases Harboring Cyclin-Dependent Kinase Pathway Alterations. Nat Cancer (2021) 2(5):498-502. doi: 10.1038/s43018-021-00198-5

103. Davies H, Bignell GR, Cox C, Stephens P, Edkins S, Clegg S, et al. Mutations of the BRAF Gene in Human Cancer. Nature (2002) 417(6892):949-54. doi: 10.1038 /nature 00766

104. Postow MA, Chesney J, Pavlick AC, Robert C, Grossmann K, McDermott D, et al. Nivolumab and Ipilimumab Versus Ipilimumab in Untreated Melanoma. N Engl J Med (2015) 372(21):2006-17. doi: 10.1056/ NEJMoa1414428

105. Reck M, Rodriguez-Abreu D, Robinson AG, Hui R, Csoszi T, Fulop A, et al. Pembrolizumab Versus Chemotherapy for PD-L1-Positive Non-Small-Cell Lung Cancer. N Engl J Med (2016) 375(19):1823-33. doi: 10.1056/ NEJMoa1606774
106. Tawbi HA, Forsyth PA, Algazi A, Hamid O, Hodi FS, Moschos SJ, et al. Combined Nivolumab and Ipilimumab in Melanoma Metastatic to the Brain. N Engl J Med (2018) 379(8):722-30. doi: 10.1056/NEJMoa1805453

107. Goldberg SB, Gettinger SN, Mahajan A, Chiang AC, Herbst RS, Sznol M, et al. Pembrolizumab for Patients With Melanoma or Non-Small-Cell Lung Cancer and Untreated Brain Metastases: Early Analysis of a NonRandomised, Open-Label, Phase 2 Trial. Lancet Oncol (2016) 17(7):97683. doi: 10.1016/S1470-2045(16)30053-5

108. Manson QF, Schrijver W, Ter Hoeve ND, Moelans CB, van Diest PJ. Frequent Discordance in PD-1 and PD-L1 Expression Between Primary Breast Tumors and Their Matched Distant Metastases. Clin Exp Metastasis (2019) 36(1):29-37. doi: 10.1007/s10585-018-9950-6

109. Khasraw M, Walsh KM, Heimberger AB, Ashley DM. What Is the Burden of Proof for Tumor Mutational Burden in Gliomas? Neuro Oncol (2020) 23 (1):17-22. doi: 10.1093/neuonc/noaa256

110. Stein MK, Pandey M, Xiu J, Tae H, Swensen J, Mittal S, et al. Tumor Mutational Burden Is Site Specific in Non-Small-Cell Lung Cancer and Is Highest in Lung Adenocarcinoma Brain Metastases. JCO Precis Oncol (2019) 3):1-13. doi: 10.1200/PO.18.00376

111. In GK, Poorman K, Saul M, O'Day S, Farma JM, Olszanski AJ, et al. Molecular Profiling of Melanoma Brain Metastases Compared to Primary Cutaneous Melanoma and to Extracranial Metastases. Oncotarget (2020) 11 (33):3118-28. doi: 10.18632/oncotarget.27686

112. Bouffet E, Larouche V, Campbell BB, Merico D, de Borja R, Aronson M, et al. Immune Checkpoint Inhibition for Hypermutant Glioblastoma Multiforme Resulting From Germline Biallelic Mismatch Repair Deficiency. JClin Oncol (2016) 34(19):2206-11. doi: 10.1200/JCO.2016.66.6552

113. Cloughesy TF, Mochizuki AY, Orpilla JR, Hugo W, Lee AH, Davidson TB, et al. Neoadjuvant Anti-PD-1 Immunotherapy Promotes a Survival Benefit With Intratumoral and Systemic Immune Responses in Recurrent Glioblastoma. Nat Med (2019) 25(3):477-86. doi: 10.1038/s41591-018-0337-7

114. Sammons S, Van Swearingen AED, Anders CK. The Promise of Immunotherapy for Breast Cancer Brain Metastases. Curr Breast Cancer Rep (2019) 11:241-7. doi: 10.1007/s12609-019-00335-1

115. Pitter KL, Casey DL, Lu YC, Hannum M, Zhang Z, Song X, et al. Pathogenic ATM Mutations in Cancer and a Genetic Basis for Radiotherapeutic Efficacy. J Natl Cancer Inst (2021) 113(3):266-73. doi: 10.1093/jnci/djaa095

116. Kim N, Kim SH, Kang SG, Moon JH, Cho J, Suh CO, et al. ATM Mutations Improve Radio-Sensitivity in Wild-Type Isocitrate DehydrogenaseAssociated High-Grade Glioma: Retrospective Analysis Using NextGeneration Sequencing Data. Radiat Oncol (2020) 15(1):184. doi: 10.3857/ roj.2020.00108

117. Pentsova EI, Shah RH, Tang J, Boire A, You D, Briggs S, et al. Evaluating Cancer of the Central Nervous System Through Next-Generation Sequencing of Cerebrospinal Fluid. J Clin Oncol (2016) 34(20):2404-15. doi: 10.1200/JCO.2016.66.6487

118. Yu HA, Arcila ME, Hellmann MD, Kris MG, Ladanyi M, Riely GJ. Poor Response to Erlotinib in Patients With Tumors Containing Baseline EGFR T790M Mutations Found by Routine Clinical Molecular Testing. Ann Oncol Off J Eur Soc Med Oncol (2014) 25(2):423-8. doi: 10.1093/annonc/mdt573

119. Salgia R. MET in Lung Cancer: Biomarker Selection Based on Scientific Rationale. Mol Cancer Ther (2017) 16(4):555-65. doi: 10.1158/15357163.MCT-16-0472

120. Fu YT, Zheng HB, Zhou L, Zhang DQ, Liu XL, Sun H. Valproic Acid, Targets Papillary Thyroid Cancer Through Inhibition of C-Met Signalling Pathway. Am J Transl Res (2017) 9(6):3138-47.

121. Kawakami H, Okamoto I, Okamoto W, Tanizaki J, Nakagawa K, Nishio K. Targeting MET Amplification as a New Oncogenic Driver. Cancers (Basel) (2014) 6(3):1540-52. doi: 10.3390/cancers6031540

122. Kabraji S, Ni J, Lin NU, Xie S, Winer EP, Zhao JJ. Drug Resistance in HER2Positive Breast Cancer Brain Metastases: Blame the Barrier or the Brain? Clin Cancer Res an Off J Am Assoc Cancer Res (2018) 24(8):1795-804. doi: 10.1158/1078-0432.CCR-17-3351

123. Kodack DP, Askoxylakis V, Ferraro GB, Fukumura D, Jain RK. Emerging Strategies for Treating Brain Metastases From Breast Cancer. Cancer Cell (2015) 27(2):163-75. doi: 10.1016/j.ccell.2015.01.001

124. Saunus JM, Quinn MC, Patch AM, Pearson JV, Bailey PJ, Nones K, et al. Integrated Genomic and Transcriptomic Analysis of Human Brain 
Metastases Identifies Alterations of Potential Clinical Significance. J Pathol (2015) 237(3):363-78. doi: 10.1002/path.4583

125. Ni J, Ramkissoon SH, Xie S, Goel S, Stover DG, Guo H, et al. Combination Inhibition of PI3K and Mtorc1 Yields Durable Remissions in Mice Bearing Orthotopic Patient-Derived Xenografts of HER2-Positive Breast Cancer Brain Metastases. Nat Med (2016) 22(7):723-6. doi: 10.1038/nm.4120

126. Kodack DP, Askoxylakis V, Ferraro GB, Sheng Q, Badeaux M, Goel S, et al. The Brain Microenvironment Mediates Resistance in Luminal Breast Cancer to PI3K Inhibition Through HER3 Activation. Sci Transl Med (2017) 9(391): eaal4682. doi: 10.1126/scitranslmed.aal4682

127. Kennecke H, Yerushalmi R, Woods R, Cheang MC, Voduc D, Speers CH, et al. Metastatic Behavior of Breast Cancer Subtypes. J Clin Oncol (2010) 28 (20):3271-7. doi: 10.1200/JCO.2009.25.9820

128. Kakadia S, Yarlagadda N, Awad R, Kundranda M, Niu J, Naraev B, et al. Mechanisms of Resistance to BRAF and MEK Inhibitors and Clinical Update of US Food and Drug Administration-Approved Targeted Therapy in Advanced Melanoma. Onco Targets Ther (2018) 11:7095-107. doi: 10.2147/OTT.S182721

129. Chen G, Chakravarti N, Aardalen K, Lazar AJ, Tetzlaff MT, Wubbenhorst B, et al. Molecular Profiling of Patient-Matched Brain and Extracranial Melanoma Metastases Implicates the PI3K Pathway as a Therapeutic Target. Clin Cancer Res an Off J Am Assoc Cancer Res (2014) 20(21):553746. doi: 10.1158/1078-0432.CCR-13-3003

130. Kavouridis VK, Harary M, Hulsbergen AFC, Lo YT, Reardon DA, Aizer AA, et al. Survival and Prognostic Factors in Surgically Treated Brain Metastases. J Neurooncol (2019) 143(2):359-67. doi: 10.1007/s11060-019-03171-6

131. Li WY, Zhao TT, Xu HM, Wang ZN, Xu YY, Han Y, et al. The Role of EGFR Mutation as a Prognostic Factor in Survival After Diagnosis of Brain Metastasis in non-Small Cell Lung Cancer: A Systematic Review and Meta-Analysis. BMC Cancer (2019) 19(1):145. doi: 10.1186/s12885-019-5331-z

132. Robin TP, Camidge DR, Stuhr K, Nath SK, Breeze RE, Pacheco JM, et al. Excellent Outcomes With Radiosurgery for Multiple Brain Metastases in ALK and EGFR Driven Non-Small Cell Lung Cancer. J Thorac Oncol (2018) 13(5):715-20. doi: 10.1016/j.jtho.2017.12.006

133. Renaud S, Seitlinger J, Falcoz PE, Schaeffer M, Voegeli AC, Legrain M, et al. Specific KRAS Amino Acid Substitutions and EGFR Mutations Predict SiteSpecific Recurrence and Metastasis Following Non-Small-Cell Lung Cancer Surgery. Br J Cancer (2016) 115(3):346-53. doi: 10.1038/bjc.2016.182

134. Johung KL, Yeh N, Desai NB, Williams TM, Lautenschlaeger T, Arvold ND, et al. Extended Survival and Prognostic Factors for Patients With ALKRearranged Non-Small-Cell Lung Cancer and Brain Metastasis. J Clin Oncol (2016) 34(2):123-9. doi: 10.1200/JCO.2015.62.0138

135. Iuchi $\mathrm{T}$, Shingyoji $\mathrm{M}$, Itakura $\mathrm{M}$, Yokoi $\mathrm{S}$, Moriya $\mathrm{Y}$, Tamura $\mathrm{H}$, et al. Frequency of Brain Metastases in Non-Small-Cell Lung Cancer, and Their Association With Epidermal Growth Factor Receptor Mutations. Int J Clin Oncol (2015) 20(4):674-9. doi: 10.1007/s10147-014-0760-9

136. Iuchi T, Shingyoji M, Sakaida T, Hatano K, Nagano O, Itakura M, et al. Phase II Trial of Gefitinib Alone Without Radiation Therapy for Japanese Patients With Brain Metastases From EGFR-Mutant Lung Adenocarcinoma. Lung Cancer (2013) 82(2):282-7. doi: 10.1016/j.lungcan.2013.08.016

137. Eichler AF, Kahle KT, Wang DL, Joshi VA, Willers H, Engelman JA, et al. EGFR Mutation Status and Survival After Diagnosis of Brain Metastasis in Nonsmall Cell Lung Cancer. Neuro Oncol (2010) 12(11):1193-9. doi: 10.1093/neuonc/noq076

138. Baek MY, Ahn HK, Park KR, Park HS, Kang SM, Park I, et al. Epidermal Growth Factor Receptor Mutation and Pattern of Brain Metastasis in Patients With Non-Small Cell Lung Cancer. Korean J Intern Med (2018) 33(1):168-75. doi: 10.3904/kjim.2015.158

139. Hsu KH, Tseng JS, Wang CL, Yang TY, Tseng CH, Chen HY, et al. Higher Frequency But Random Distribution of EGFR Mutation Subtypes in Familial Lung Cancer Patients. Oncotarget (2016) 7(33):53299-308. doi: 10.18632/ oncotarget.10715

140. Duffy MJ, Harbeck N, Nap M, Molina R, Nicolini A, Senkus E, et al. Clinical Use of Biomarkers in Breast Cancer: Updated Guidelines From the European Group on Tumor Markers (EGTM). Eur J Cancer (2017) 75:284-98. doi: 10.1016/j.ejca.2017.01.017

141. Owens MA, Horten BC, Da Silva MM. HER2 Amplification Ratios by Fluorescence in Situ Hybridization and Correlation With
Immunohistochemistry in a Cohort of 6556 Breast Cancer Tissues. Clin Breast Cancer (2004) 5(1):63-9. doi: 10.3816/CBC.2004.n.011

142. Onitilo AA, Engel JM, Greenlee RT, Mukesh BN. Breast Cancer Subtypes Based on ER/PR and Her2 Expression: Comparison of Clinicopathologic Features and Survival. Clin Med Res (2009) 7(1-2):4-13. doi: 10.3121/cmr.2008.825

143. Galluzzi L, Kepp O, Tajeddine N, Kroemer G. Disruption of the HexokinaseVDAC Complex for Tumor Therapy. Oncogene (2008) 27(34):4633-5. doi: 10.1038/onc.2008.114

144. Pedersen PL. Voltage Dependent Anion Channels (VDACs): A Brief Introduction With a Focus on the Outer Mitochondrial Compartment's Roles Together With Hexokinase-2 in the "Warburg Effect" in Cancer. J Bioenerg Biomembr (2008) 40(3):123-6. doi: 10.1007/s10863-008-9165-7

145. Schulten HJ, Bangash M, Karim S, Dallol A, Hussein D, Merdad A, et al. Comprehensive Molecular Biomarker Identification in Breast Cancer Brain Metastases. J Transl Med (2017) 15(1):269. doi: 10.1186/s12967-017-1370-x

146. Pleasance E, Titmuss E, Williamson L, Kwan H, Culibrk L, Zhao EY, et al. Pan-Cancer Analysis of Advanced Patient Tumors Reveals Interactions Between Therapy and Genomic Landscapes. Nat Cancer (2020) 1(4):45268. doi: 10.1038/s43018-020-0050-6

147. Priestley P, Baber J, Lolkema MP, Steeghs N, de Bruijn E, Shale C, et al. PanCancer Whole-Genome Analyses of Metastatic Solid Tumours. Nature (2019) 575(7781):210-6. doi: 10.1038/s41586-019-1689-y

148. Mahal BA, Alshalalfa M, Kensler KH, Chowdhury-Paulino I, Kantoff P, Mucci LA, et al. Racial Differences in Genomic Profiling of Prostate Cancer. N Engl J Med (2020) 383(11):1083-5. doi: 10.1056/NEJMc2000069

149. van der Velden DL, van Herpen CML, van Laarhoven HWM, Smit EF, Groen HJM, Willems SM, et al. Molecular Tumor Boards: Current Practice and Future Needs. Ann Oncol Off J Eur Soc Med Oncol (2017) 28(12):3070-5. doi: 10.1093/annonc/mdx528

150. Laskin J, Jones S, Aparicio S, Chia S, Ch'ng C, Deyell R, et al. Lessons Learned From the Application of Whole-Genome Analysis to the Treatment of Patients With Advanced Cancers. Cold Spring Harb Mol Case Stud (2015) 1(1):a000570. doi: 10.1101/mcs.a000570

151. Schwaederle M, Parker BA, Schwab RB, Fanta PT, Boles SG, Daniels GA, et al. Molecular Tumor Board: The University of California-San Diego Moores Cancer Center Experience. Oncologist (2014) 19(6):631-6. doi: 10.1634/theoncologist.2013-0405

152. Keating NL, Landrum MB, Lamont EB, Bozeman SR, Shulman LN, McNeil BJ. Tumor Boards and the Quality of Cancer Care. J Natl Cancer Inst (2013) 105(2):113-21. doi: 10.1093/jnci/djs502

Conflict of Interest: CA receives research funding from PUMA, Lilly, Merck, Seattle, Genetics, Nektar, Tesaro, G1-Therapeutics, ZION, Novartis, and Pfizer; a compensated consultant role from Genentech (1/2019-), Eisai (1/2019-), IPSEN (2/2019-), Seattle Genetics (11/15/2019-11/15/2020), Astra Zeneca (3/2020-6/ 2020), Novartis (5/2020-5/2022), Immunomedics (10/1/2020-9/22/2021), Elucida (9/2020), and Athenex (2/2021-2/2023); and royalties from UpToDate and Jones and Bartlett. AS receives research funding (paid to institution) from Bristol Myers Squibb, Immunocore and Merck and a compensated consultant role from Novartis, Pfizer, Iovance, and Regeneron. ZR receives royalties for intellectual property related to cancer molecular diagnostic testing that has been licensed to Genetron Health and is managed by Duke University. JC receives research funding (as PI) from Bristol-Myers Squibb, Genentech, Spectrum, Adaptimmune, Medpacto, Bayer, AbbVie, Moderna, GlaxoSmithKline, Array, AstraZeneca, Grid Therapeutics, and CBMG; speaker at Merck and AstraZeneca; adviser at AstraZeneca (10/2018, 10/26/19), Guardant (12/18/18), Merck (3/8/19), Pfizer (1/ 10/20), NGM Biopharmaceuticals (1/20/20), Spectrum (9/18/20), Genentech (11/ 1/20); travel from Merck, AstraZeneca, Pfizer, and NGM Bio; Board of Directors at Lung Cancer Initiative of North Carolina (uncompensated); and DMSC at G1 Therapeutics.

The remaining authors declare that the research was conducted in the absence of any commercial or financial relationships that could be construed as a potential conflict of interest.

Publisher's Note: All claims expressed in this article are solely those of the authors and do not necessarily represent those of their affiliated organizations, or those of the publisher, the editors and the reviewers. Any product that may be evaluated in 
this article, or claim that may be made by its manufacturer, is not guaranteed or endorsed by the publisher.

Copyright $\odot 2022$ Shen, Van Swearingen, Price, Bulsara, Verhaak, Baëta, Painter, Reitman, Salama, Clarke, Anders, Fecci, Goodwin and Walsh. This is an open-access article distributed under the terms of the Creative Commons Attribution License (CC BY). The use, distribution or reproduction in other forums is permitted, provided the original author(s) and the copyright owner(s) are credited and that the original publication in this journal is cited, in accordance with accepted academic practice. No use, distribution or reproduction is permitted which does not comply with these terms. 